\title{
Bathimetri di perairan pantai depan Sungai Bahu, Kecamatan Malalayang, Manado
}

\author{
Bathymetry in coastal waters off Bahu River mouth, Malalayang District, Manado
}

\author{
WANDASARI HAMID*, FRANGKY E. KAPARANG dan HEFFrY V. DIEN \\ Program Studi Pemanfaatan Sumberdaya Perairan Fakultas Perikanan dan Ilmu Kelautan \\ Universitas Sam Ratulangi Manado, 95115
}

\begin{abstract}
The word bathymetry come from the Greek. Bathy is depth and metry is the science of measurement. So bathymetry can be defined as the science of measuring and mapping the bottom of waters. It is necessary to have accurate data about the physical state of the waters like shape of the coastline, tidal height and the shape of seabed. So that the objectives of this study are: to map the shape of the coastline, the state of tides and to describe the contours of the seabed. Collecting data using a water depth transect pattern normal to coastline. Tidal height measured using a tide pole. Results showed that the length of the surveyed coastline was 1,327 meters stretching from position $1^{0} 27^{\prime} 39.9^{\text {"- }}$ $124^{0} 49^{\prime} 13.7^{\prime \prime} \mathrm{N}$ to $1^{0} 27^{\prime} 34.0$ " $-124^{0} 49^{\prime} 03.0^{\prime \prime}$ E. Sea level at high tide was $204 \mathrm{~cm}$ high at $05.00 \mathrm{pm}$ and low tide (10 $\mathrm{cm})$ occurred at $00.00 \mathrm{pm}$. Seabed of Malalayang coastal waters has two basic forms; at north the depth was more than $100 \mathrm{~m}$ and the contour was very steep, while at northwest of the study location had the depth of less than $100 \mathrm{~m}$ and shape sloping beaches with contour lines rather far apart.
\end{abstract}

Keywords: bathymetry, Bahu River, Malalayang District

\begin{abstract}
ABSTRAK
Kata bathimetri berasal dari bahasa Yunani yaitu Bathy adalah kedalaman dan metry ialah ilmu tentang pengukuran. Sehingga Bathymetri dapat didefinisikan sebagai ilmu tentang pengukuran dan pemetaan dasar perairan. Untuk itu diperlukan data yang akurat tentang keadaan fisik perairan seperti bentuk garis pantai, pasang surut kedalaman perairan dan bentuk dasar laut. Sehingga yang menjadi tujuan dari penelitian ini adalah: untuk memetakan bentuk garis pantai, keadaan pasang surut dan menggambarkan kontur dasar laut. Survei dilakukan dengan menggunakan metode sounding. Pengambilan data kedalaman perairan mengikuti pola transek yang tegak lurus garis pantai. Tinggi pasang surut diukur dengan palem pasut. Hasil penelitian bahwa panjang garis pantai lokasi penelitian adalah 1.327 meter yang terbentang dari posisi $1^{0} 27^{\prime} 39.9^{\prime \prime}-124^{0} 49^{\prime} 13.7^{\prime \prime}$ LU sampai $1^{0} 27^{\prime} 34.0^{\prime \prime}-124^{0} 49^{\prime} 03.0^{\prime \prime}$ BT. Tinggi permukaan air laut pada saat pasang tertinggi yaitu $204 \mathrm{~cm}$ pada pukul 17.00 WITA dan surut terendah $(10 \mathrm{~cm})$ terjadi pada pukul 00.00 WITA. Keadaan dasar perairan di pantai Malalayang memiliki 2 bentuk dasar perairan yakni dibagian utara memiliki tingkat kedalaman yang lebih besar dari 100 meter dan bentuk pantainya adalah lereng terjal dengan garis kontur yang berdekatan, sedangkan barat laut dari lokasi penelitian memiliki tingkat kedalaman yang kurang dari 100 meter dan bentuk pantainya landai dengan garis kontur yang agak berjauhan.
\end{abstract}

Kata-kata kunci: bathimetri, Sungai Bahu, Kecamatan Malalayang

\section{PENDAHULUAN}

Laut mempunyai peranan yang sangat penting bagi kehidupan dan masa depan bangsa Indonesia, di dalamnya terkandung berbagai macam sumberdaya yang merupakan sumber devisa bagi negara,

\footnotetext{
* Penulis untuk penyuratan; email: wandhasari85@yahoo.com
}

namun hingga saat ini pemanfaatan dan pengelolaan sumberdaya tersebut belum sepenuhnya ditangani sehingga masih perlu untuk ditingkatkan lagi (Haeruman, 1994). Dengan semakin beragamnya kegiatan yang berhubungan dengan laut seperti pembangunan pelabuhan, pemasangan maupun pemeliharaan pipa bawah laut, kabel bawah laut, eksplorasi minyak dan gas, maka 
diperlukan pemetaan bathimetri dengan wilayah cakupan yang semakin luas (Tambayong, 1985).

Wilayah pesisir Kecamatan Malalayang, Kota Manado merupakan suatu wilayah perairan yang strategis dalam pengembangan sebagai lokasi pemukiman, industri, perikanan, dan pariwisata di Kota Manado, Provinsi Sulawasi Utara. Untuk itu diperlukan data yang akurat tentang keadaan fisik perairan seperti bentuk garis pantai, pasang surut (pasut) kedalaman perairan dan bentuk dasar laut. Sehingga yang menjadi tujuan dari penelitian ini adalah: untuk memetakan bentuk garis pantai, keadaan pasang surut dan menggambarkan kontur dasar laut.

\section{METODE PENELITIAN}

Secara gografis lokasi penelitian terletak di antara $1^{0} 25^{\prime} 88^{\prime \prime}-1^{0} 39^{\prime} 50^{\prime \prime}$ LU dan $124^{\circ} 47^{\prime} 00^{\prime \prime}$ BT, dengan batas administratif sebelah Utara berbatasan dengan Teluk Manado, Timur berbatasan dengan Kelurahan Bahu, Selatan berbatasan dengan Krida, Barat berbatasan dengan Malalayang.

Pengambilan data kedalaman perairan mengikuti pola transek yang tegak lurus garis pantai. Dengan cara mengikuti koordinat lintang yang dimulai dari kedalaman 1 meter ke arah laut sampai pada batas kedalaman (isobath) \pm 150 untuk jalur berikutnya diukur dari arah laut ke arah darat sampai pada kedalaman 1 meter, hal ini berulang sampai pada transek terakhir. Penentuan arah dan posisi jalur sounding dibantu dengan kompas dan GPS. Pengambilan data posisi geografis dan kedalaman dasar laut dilakukan setiap perubahan kedalaman sepanjang garis transek. Kedalaman dasar perairan diukur dengan GPS Finder dengan tipe (GPS MAP Garmin 580). Data yang dicatat adalah posisi geografis, jarak antara titik pengukuran dengan garis pantai dan kedalaman dasar perairan $(\mathrm{m})$.

Hasil pengambilan data garis pantai untuk setiap titik koordinat, diplotkan di dalam tabel secara berurutan, dengan memperhatikan tandatanda khusus yang diberikan pada masing-masing titik koordinat kemudian data tersebut di masukkan ke dalam Microsoft Word dan Surver 10. Dari titik-titik koordinat yang di plot di Surver akan dihubungkan dengan garis secara berurutan. Sehingga terbentuklah gambar garis pantai.

Pengukuran pasut menggunakan cara pengamatan langsung (Djaja 1989) yaitu dengan membaca skala pada palem pasut yang berimpit dengan permukaan air laut dengan jangka waktu tertentu. Pengamatan dan pencatatan tinggi air dilakukan berdasarkan nilai yang tertera pada palem pasut yang dilakukan setiap 1 jam selama 24 jam.

Hasil pengukuran kedalaman melalui tiang pasut disajikan dalam bentuk tabel dan dikelompokkan berdasarkan waktu pengamatan pasang surut yang dilakukan dengan interval 15 menit. Data kedalaman dari hasil pengukuran ditambah dengan kedalaman dari GPS finder yang dibenamkan dibawah permukaan air, kemudian ditambahkan atau dikurangi dengan nilai pasang terkoreksi untuk masing-masing kelompok pengukuran berdasarkan waktu pengamatan, apakah berada diatas atau dibawah nilai MSL, maka nilai kedalaman tersebut dikurangkan. Dengan kata lain data ini dapat dianalisis dengan menggunakan rumus (Anonim, 1995) sebagai berikut :

$$
\mathrm{H}_{\text {plot }}=\mathrm{H}_{\mathrm{ukur}}+\mathrm{H}_{\mathrm{T}} \pm \mathrm{H}_{\mathrm{pas}}
$$

di mana :

$\mathrm{H}_{\text {plot }}=$ Kedalaman terkoreksi yaitu kedalaman perairan laut MSL

$\mathrm{H}_{\mathrm{ukur}}=$ Kedalaman terkoreksi selama sounding

$\mathrm{H}_{\mathrm{T}}=$ Kedalaman transduser

$\mathrm{H}_{\text {pas }}=$ Tinggi muka air dari MSL saat sounding

Selanjutnya nilai hasil pengamatan pasang surut tersebut dijumlahkan kemudian dibagi dengan jumlah pengamatan, maka diperoleh mean sea level (MSL). Rumus untuk mencari MSL adalah sebagai berikut :

$$
\mathrm{MSL}=\frac{\sum \text { Nilai pasang surut }}{\text { Pengamatan }}
$$

\section{HASIL DAN PEMBAHASAN}

\section{Pemetaan garis pantai}

Garis pantai barat daya Kota Manado di Perairan depan Sungai Bahu dan sekitarnya Kecamatan Malalayang ini terbentang 1027'39.9' LU-124 49'13.7" BT sampai 1027'34.0' LU-124049'03.0" BT dengan jarak 1.327 meter dengan skala peta 1 : 9.338. (Gbr. 1).

Berdasarkan hasil pengukuran garis pantai daerah yang berpasir terbentang dari posisi $1^{0} 27^{\prime} 39.9^{\prime \prime}$ LU-124049'13.7” BT dan $1^{0} 27^{\prime} 39.5^{\prime \prime}$ 
LU-124049'12.4" BT dengan jarak 12,35 meter. Pantai yang memiliki campuran antara pasir dan kerikil terbentang dari posisi $1^{0} 27^{\prime} 39.4$ " LU$124^{0} 49^{\prime} 12.3^{\prime \prime}$ BT dan $1^{0} 27^{\prime} 39.2^{\prime \prime}$ LU-124049'11.3" BT dengan jarak 6,17 meter, bebatuan besar terbentang dari posisi $1^{0} 27^{\prime} 39.1$ " LU-124049'11.2" BT sampai $1^{0} 27^{\prime} 34.0^{\prime \prime}$ LU-124 49'03.0” BT dengan jarak 157,42 meter.

\section{Pengukuran pasang surut}

Berdasarkan hasil pengamatan pasang tertinggi tercapai pada pukul 17.00 dengan kisaran muka laut mencapai $204 \mathrm{~cm}$ dan surut terendah mencapai $10 \mathrm{~cm}$ pada pukul 00.00 (Gbr. 2).

\section{Pengukuran kedalaman perairan}

Hasil pengukuran kedalaman ini diukur dari arah utara ke barat kemudian selatan ke utara. Data yang dibuat terdiri dari 8 lajur di mana kedalamannya dimulai dari 3 meter sampai 135 meter. Pada pelaksanaan pemetaan kontur dasar laut di mana pembuatan interval isodepth adalah 3 , $9,15,21,27,33,39,45,51,57,63,69,75,81,87$, $93,99,105,111,117,123,129,135$. (Gbr. 3\&4).

Gambar 3 dan 4 menggambarkan bahwa lokasi penelitian dipantai Malalayang memiliki 2 bentuk dasar perairan yakni di bagian utara memiliki tingkat kedalaman yang lebih besar dari 100 meter dan bentuk pantainya adalah lereng terjal dengan garis kontur yang berdekatan, sedangkan barat laut dari lokasi penelitian memiliki tingkat kedalaman yang kurang dari 100 meter dan bentuk pantainya landai dengan garis kontur yang agak berjauhan.

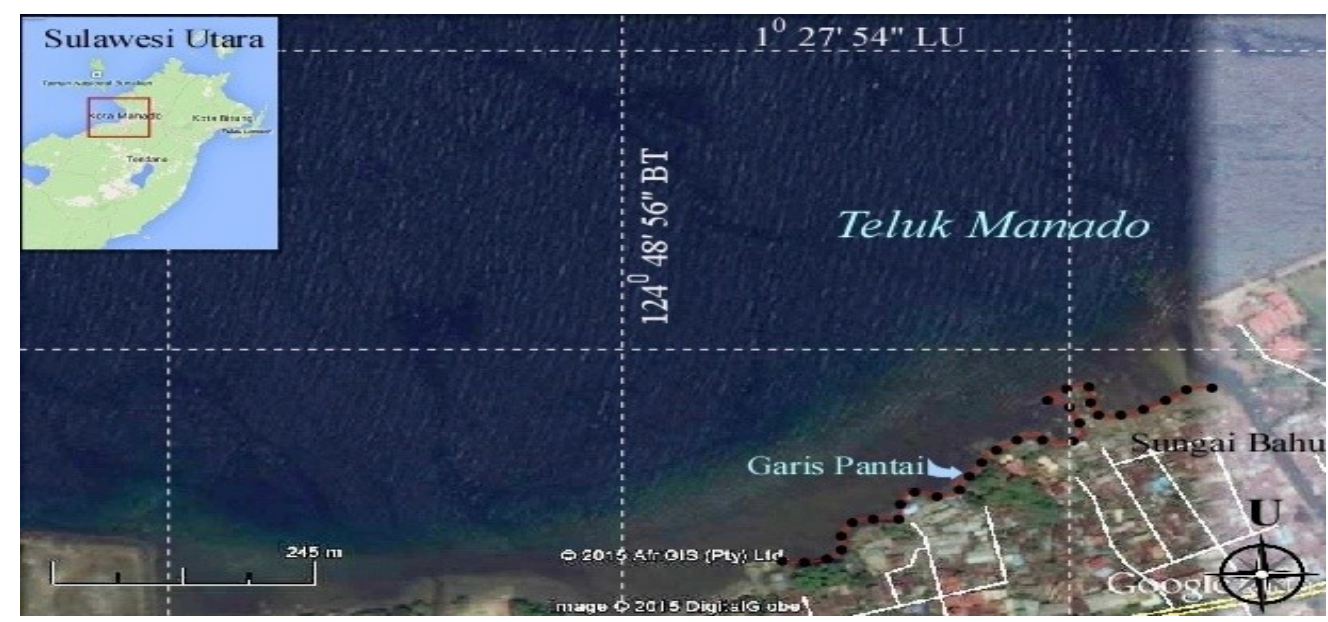

Gambar 1. Hasil pengukuran garis pantai

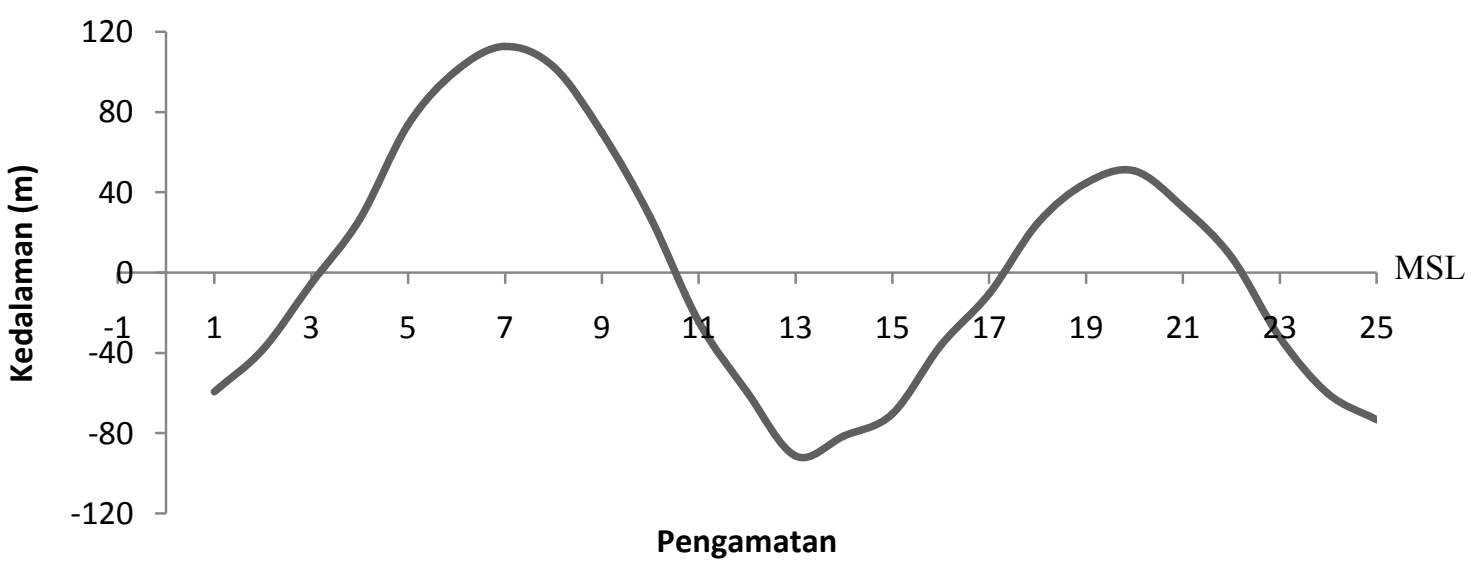

Gambar 2. Tinggi Pasut pada saat penelitian 
W. Hamid dkk.

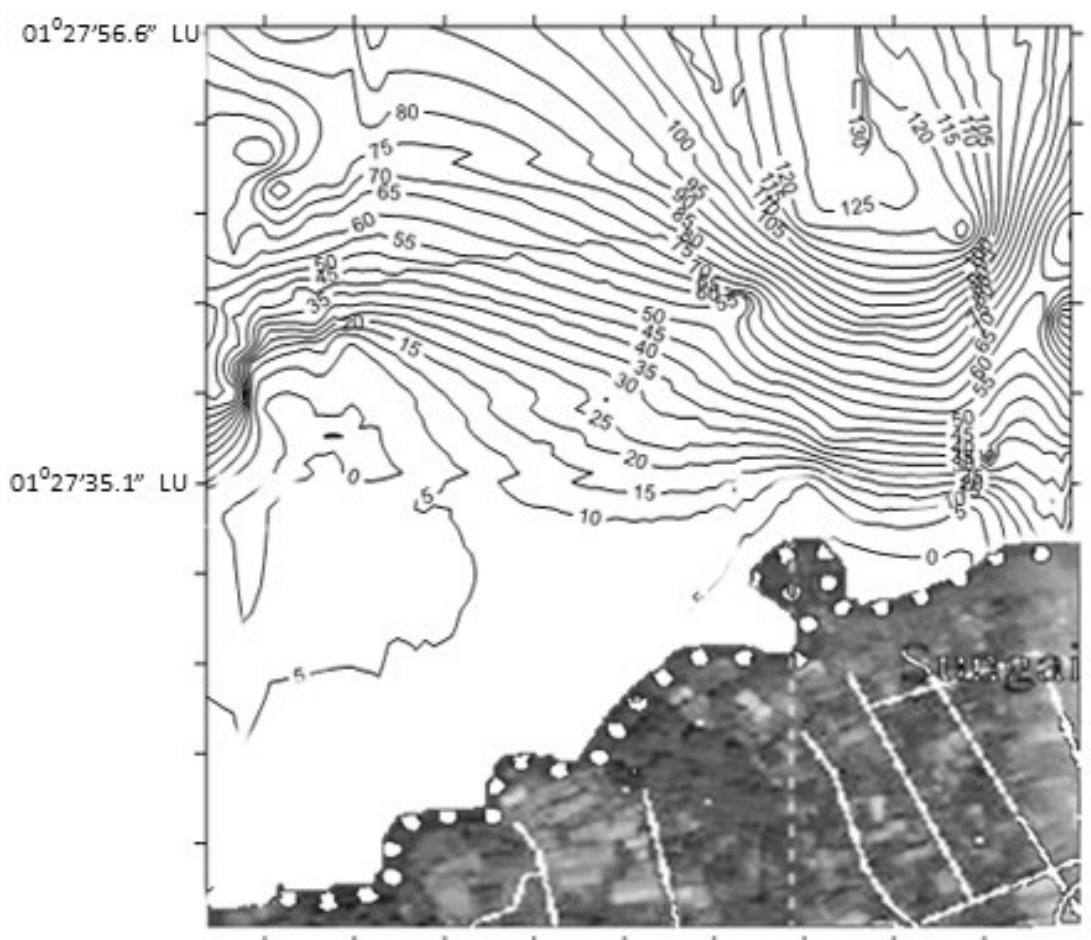

$124^{\circ} 49^{\prime} 0.9^{\prime \prime} \mathrm{BT}$

$124^{\circ} 49^{\prime} 59.8^{\prime \prime} \mathrm{BT}$

Gambar 3. Pemetaan dasar laut lokasi penelitian

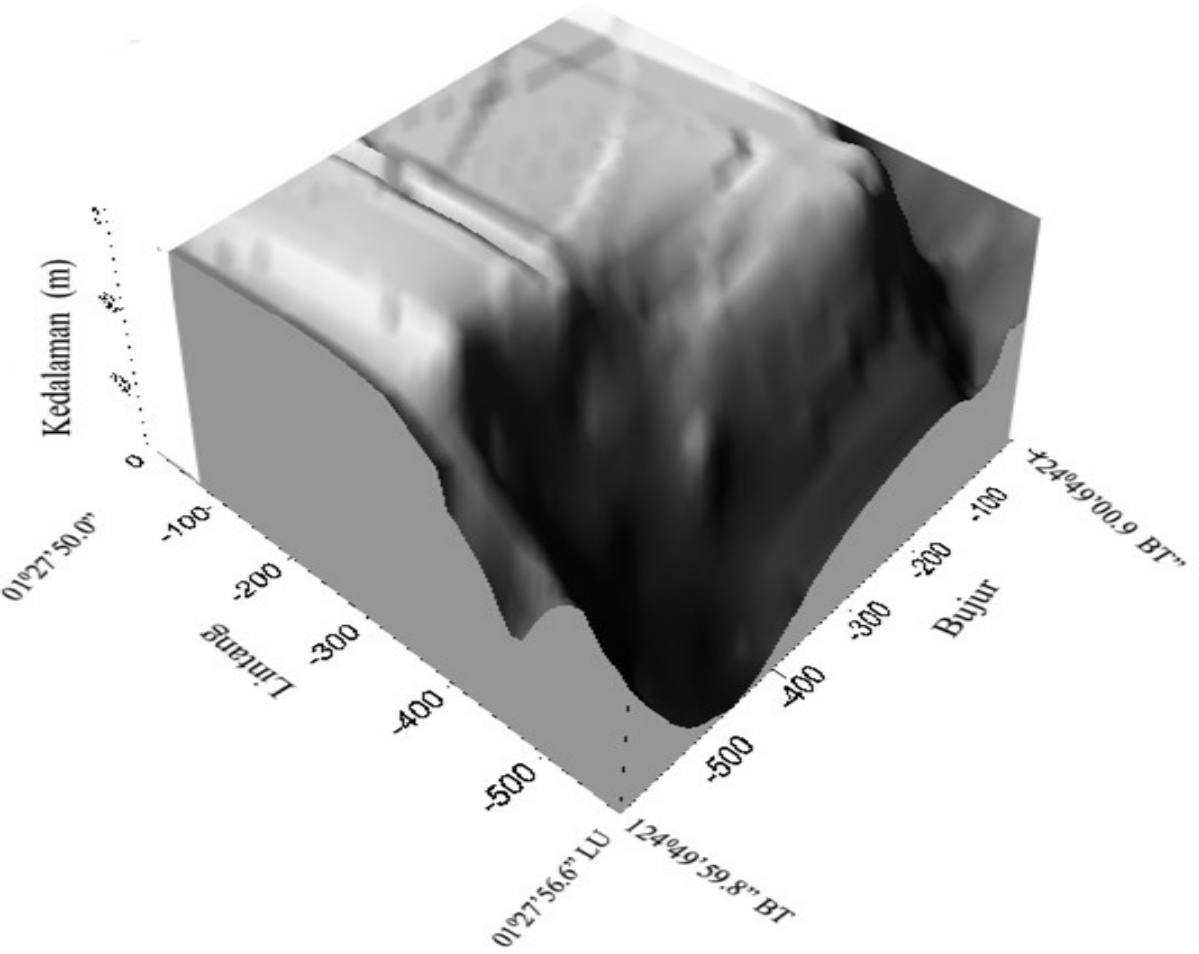

Gambar 4. Profil kontur dasar laut 


\section{KESIMPULAN}

1. Panjang garis pantai lokasi penelitian adalah 1.327 meter yang terbentang dari posisi $1^{0} 27$ '39.9"-124049'13.7" LU sampai $1^{0} 27^{\prime} 34.0^{\prime \prime}-124^{0} 49^{\prime} 03.0^{\prime \prime}$ BT.

2. Tinggi permukaan air laut pada saat pasang tertinggi yaitu $204 \mathrm{~cm}$ pada pukul 17.00 WITA dan surut terendah $(10 \mathrm{~cm})$ terjadi pada pukul 00.00 WITA.

3. Keadaan dasar perairan pada lokasi penelitian di pantai Malalayang memiliki 2 bentuk dasar perairan yakni dibagian utara memiliki tingkat kedalaman yang lebih besar dari 100 meter dan bentuk pantainya adalah lereng terjal dengan garis kontur yang berdekatan, sedangkan barat laut dari lokasi penelitian memiliki tingkat kedalaman yang kurang dari
100 meter dan bentuk pantainya landai dengan garis kontur yang agak berjauhan.

\section{DAFTAR PUSTAKA}

Anonimous. 1995. Profil kelautan nasional menuju kemandirian. Panitia Pengembangan Riset dan Teknologi Kelautan Serta Industri Maritim (PTK), Jakarta.

Haeruman, H. 1994. Aspek ekonomi dalam pembangunan yang berwawasan lingkungan di Indonesia. Procedings Seminar Teknik Pantai 1993. LPTP-BPP Teknologi, Yogyakarta.

Katoppo, P.L. 1985. Peran hidro oseonografi dalam pembangunan dan pertahanan nasional. Diklat Kuliah Pendidikan Survey Laut Rekayasa. ITBBAKOSURTANAL, Bandung.

Tambayong, R. 1985. Introduksi survey hidrologi untuk rekayasa. Diktat Kuliah Pendidikan Survey Laut rekayasa ITB-BAKOSURTANAL, Bandung. 